\title{
LAS ESTRATEGIAS DE LA MEMORIA: JULIO CORTÁZAR RECORDADO POR MARIO VARGAS LLOSA (ANÁLISIS SEMIOLÓGICO)
}

\author{
Manuel González de Ávila
}

(Universidad de Salamanca)

1. La memoria, es cosa sabida, juega malas pasadas: a uno mismo, pero también, - $-\mathrm{y}$ acaso principalmente-, al otro. El artículo de Mario Vargas Llosa La trompeta de Deyá (El País, 28 de julio de 1991), dedicado a rememorar la figura del desaparecido Julio Cortázar, se diría escrito para confirmación de tan banal verdad. No se trata de un texto críptico que vele maliciosamente un significado oculto; antes bien, su lectura opone escasa resistencia a la comprensión. Pero un reordenamiento detallado de sus componentes acaso arroje alguna turbia luz sobre lo que la letra dice con tan cegadora claridad ${ }^{1}$

2. El texto implanta en la SC 2 un Sujeto dual, compuesto por dos actores distintos, S1 (Julio Cortázar) y S2 (Aurora), reunidos en un sólo actante sincrético y caracterizados precisamente por lo acabado de su sincretismo. Semejante avenencia intersubjetiva provoca en el SE una mara-

1 Este análisis se ha llevado a cabo utilizando buen número de conceptos creados por la Escuela de París. Prescindimos de dar, por demasiado extensa, la nómina entera de fuentes y deudas. Las pocas abreviaturas que figuran en el texto son: S: sujeto; SE: sujeto enunciador; SC: secuencia; PN: programa narrativo. 
villada sorpresa, que nace de la observación de la actividad de aquéllos, de su /hacer/, lexicalizado en el verbo conversar, con el que comienza el recorrido figurativo inicial del texto, el /diálogo/, - al que se le supone un alcance privado-. El tema, el Objeto de la conversación es la /literatura/. El hacer-operador /conversación literaria/, subsumido en la más amplia estructura del /diálogo/, es prontamente axiologizado por medio de un encarecimiento hiperbólico: conversación asombrosa = «espectáculo», hipérbole que refuerza la compacta coherencia del Sujeto dual (comparado con dos acróbatas), sujeto agente de una exclusión constitutiva: del /hacer//conversación literaria/ «todos los demás parecíamos sobrar». El Sujeto doble manifiesta así los atributos que lo singularizan: la autonomía radical con respecto a los restantes sujetos virtuales de su entorno y la maestría con la que rige su actividad autosuficiente.

3. Dentro del fragmento de representación discursiva /diálogo/ el Sujeto dual actúa de acuerdo con tres roles temáticos que a su vez implican tres formas distintas de su competencia.

\begin{tabular}{|c|c|c|}
\hline Roles & Competencias & Textualización \\
\hline /pareja ideal/ & /psicológica/ & $\begin{array}{l}\text { «perfecta complicidad»-«secreta } \\
\text { inteligencia» }\end{array}$ \\
\hline /intelectuales brillantes/ & /cognoscitiva/ & habilidad dialéctica y cultural de la pareja \\
\hline lamira dminhlo & /ético-social/ & $\begin{array}{l}\text { «simpatía, generosidad con todo el } \\
\text { mundo» }\end{array}$ \\
\hline
\end{tabular}

Roles y competencias conforman la definición estática y dinámica, calificativa y funcional, del Sujeto doble, pues son un inventario exhaustivo $\mathrm{de}$ su /ser/ y de su /hacer/ frente a los demás, dando vida a la actualización apenas disimulada de una figura actorial mítica: el andrógino perfecto.

4. El texto, hasta aquí, ha construido una unidad de relato completa y acabada, un programa narrativo, en cuya formulación sólo quedan irresueltas dos incógnitas: el par Destinador-Destinatario. El Destinador no es otro que el propio Sujeto doble en la medida en que se muestra capaz de automotivarse y de elegir su acción. Y en cuanto al Destinatario del PN, habrá que avanzar en la lectura del texto antes de reconocer su perfil. Todos los componentes parciales del programa aparecen de hecho subordinados al presunto sincretismo sin falla del Sujeto doble: el PN que componen es el de una /realización conyugal/, donde se reúnen y armonizan tanto el carácter de «matrimonio feliz» del Sujeto sincrético, hecho explícito en la SC 11 y asumido directamente en la SC 2 por el rol dominante /pareja ideal/, como su capacidad intelectual y su apertura ética hacia el prójimo. Este primer PN se coloca bajo la sanción admirativa del SE, pero el discurso de la memoria (enunciación) va tejiendo toda una red de autocorreciones retroactivas que matizan el estatuto veridictorio del exquisito entendimiento mutuo entre los cónyuges (enunciado): «todos» pareciamos 
«sobrar»; "parecía unirlos»; "daba la impresión de» (SC 2); tales autocorrecciones activan el polo /no - ser + parecer $=$ mentira/ del cuadrado de la veridicción; y la /mentira/ sorprende, claro está, a un observador no receloso: «Pocos días después recibí carta de Julio anunciándome su separación. Creo que nunca me he sentido tan despistado» (SC 11).

PN 1 /realización conyugal/

$$
\text { SUJETO } 1+2
$$

Destinador:

Sujeto:

Destinatario:

Recorrido figurativo:

Operador:

Objeto:
$\mathrm{S} 1+\mathrm{S} 2 \quad$ Roles

$\mathrm{S} 1+\mathrm{S} 2$

$/ \mathrm{i} \times$ ?

/diálogo privad./

/conv. literaria/

/literatura/
Competen.

/pareja ideal/

/psicológica/

/amigos admirables/ /ético-social/

/intelectuales brillantes/ /cognoscitiva/ ${ }^{2}$

5. Pero la SC 2 lleva ya en su interior el germen lexemático -el «compromiso con la literatura» del Sujeto dual - de un PN 2, destinado a expandirse y a absorber el PN 1 /realización conyugal/, al que convertirá en mero auxiliar, en PN de uso. El PN 1 había sido sancionado incluso antes de que se detallase su tenor («nunca dejé de maravillarme con el espectáculo...»), lo que agota sus posibilidades de desarrollo: tal programa ya está cumplido. El PN 2, dominante o jerárquicamente superior, se organizará en torno a un Objeto literario similar, lo que hace posible el cambio, la articulación narrativa entre programas, pero poseerá otro Sujeto y otras características bien diferentes.

6. Éstos son los tres enunciados paradigmáticamente conexos que definen en toda su amplitud el PN 2:

SC 2: [...] su compromiso con la literatura, que daba la impresión de ser exclusivo, excluyente y total...

SC 7: Era un hombre eminentemente privado, con un mundo interior construido y preservado como una obra de arte al que probablemente sólo Aurora tenía acceso, y para el que nada, fuera de la literatura, parecía importar, acaso existir.

SC 13: [...] como dijo, la existencia se resumía para él en un libro.

La SC 2 es una formulación directa del nuevo programa, adjudicado todavía al Sujeto dual, en tanto que en las siguientes el Sujeto se escinde y ya es sólo el S1 quien encabeza el programa, quedando eliminado el S2.

${ }^{2}$ Las correspondencias entre roles y competencias no son biunivocas ni matematizables, pues se implican las unas a las otras en conjunto. Se trata de meras descripciones aproximativas que sólo intentan proporcionar una primera estructuración al discurso complejo del texto. 
La SC 7 introduce la categoría sémica topológica /exterioridad vs. interioridad/ para caracterizar a la /existencia/, reduciendo la /existencia exterior/ del S1 a cero e implantando en el espacio /existencia interior/, como su Objeto único, la /literatura/ (operación modelizada, como de costumbre, y al igual que la secuencia previa, por el /parecer/. Dejamos para más tarde el análisis de la función desempeñada por el S2 en ella)

La SC 13 anaforiza la precedente y condensa de nuevo, también con respecto al S1, la /existencia/ en el Objeto/literatura/, representado esta vez por el lexema metonímico libro. Ahora bien, mientras que en las secuencias anteriores es el SE el responsable de los juicios emitidos, en ésta el SE se limita a reproducir el discurso del propio S1 sobre sí mismo («como dijo...», enunciación enunciada), con lo que el conjunto del proceso reductor gana en verosimilitud, dejando el plano del /parecer/ para instalarse en el del /ser/ (ya que se sobreentiende que en este caso no hay razón para que el S1 se engañe ni quiera engañar cuando habla de sus objetivos vitales personales).

A este PN 2: lo llamaremos /realización artística/. Y, puesto que antes habíamos reconocido que el primer programa estaba globalmente subordinado al segundo, podemos postular que en el mismo movimiento hemos descubierto el nombre del verdadero Destinatario o Beneficiario del PN 1 /realización conyugal/: el entero bloque del PN 2 /realización artística/, que no lograría articularse sin el PN 1, su condición de posibilidad textual. Con ello queda completo el esquema precedente.

7. ¿Cómo desaparece el S2 del PN 2 /realización artística/? El texto no lo borra simplemente, sino que disminuye su categoría actancial, pasándolo de co-Sujeto y de co-Destinador en el PN 1 a Ayudante en el PN 2. La espléndida simetría del Sujeto doble se rompe y al pleno ajuste de sus competencias en el primer programa sucede una disparidad radical de sus ejecuciones respectivas en el segundo. El S1 obtiene en el PN 2 un Objeto de valor pleno, la /obra literaria propia/; el S2, tan sólo un Objeto de valor disminuido, la /obra literaria ajena/ (labor de traducción-recreación). El S2 declina su competencia y su teleología en favor del S1, desmedramiento actancial que es un genuino "sacrificio» (SC 3); queda así salvaguardada la supervivencia del PN 1 de uso/realización matrimonial/, condición de posibilidad del PN 2. Pero esta renuncia del S2 a su propia sanción como sujeto realizado en el PN 2, que permite el cumplimiento del S1 en ese mismo programa, cambia a su vez a éste de co-Sujeto y co-Destinatario en anti-Destinador del S2, haciéndole reunir en sí los poco graciosos rasgos de Sujeto ayudado por y de Sujeto represor (anti-Destinador) del S2. ¿Y qué mejor definición posible del egoismo? El SE reacciona vigorosamente contra este hecho calificándolo por tres veces de circunstancial: «algo provisional», "un transitorio sacrificio», «hubiera de momento un solo escritor) (SC 3). Al-SE le tienta incluso otorgar a posteriori al S2 la sanción de su antaño no realizado PN 2, preguntándole en la SC 4 si «tiene muchas 
cosas escritas, si va a decidirse por fin a publicar", con lo que el SE se ofrece a hacer las veces de Destinador final retributivo, glorificador, del S2, reemplazando y enfrentándose en esa tarea... al anti-Destinador represivo S1, juez y parte interesada en el «sacrificio» del S2. Un escrúpulo se lo impide, sin embargo, pues «se muerde la lengua» antes de hacerlo, consciente de que tal pregunta vela una acusación tácita contra el $\mathrm{S} 1 . .$. aunque ese gesto de autocensura presupone en el S2 la misma conciencia acerca de la injusticia de su vínculo disimétrico con el Sujeto 1 durante el PN /realización artística/. Lo que equivale a proyectar sobre el S2 la responsabilidad de un juicio hipotético -el presunto desequilibrio del Sujeto dual-, que por el momento no es sino una inferencia del SE, pero inferencia que, una vez proyectada sobre el S2 -al que se obliga así a compartirla a la fuerza - cobra certidumbre y funciona como petición de principio, con valor que se pretende demostrativo, en un razonamiento lógicamente viciado (desde esta perspectiva el fallecimiento del S1 trae consigo la liberación del S2 del perjudicial contrato que lo ligaba al S1, su anti-Destinador).

8. El Objeto del nuevo programa aparece en la SC 6, «temas fantásticos» - parafraseable en /literatura de imaginación/—, dando forma al rol /creador literario/ del S1. Este Objeto recibe dos determinaciones:

«Temas fantásticos»

DT 1: SC 6 : «apariencia cotidiana, doméstica y risueña»

DT 2: SC 7: «fondo inquietante, irracional y violento»

Reduciendo las oposiciones léxicas del nivel superficial o discursivo - del revestimiento textual-, a las categorias semánticas de base que realizan:

$\frac{\text { DT 1: Apariencia: cotidiana, doméstica, risueña }}{\text { DT 2: Fondo: inquietante, irracional, violento }}=\frac{\text { Parecer: } \text { eufórico: } \text { inocencia }}{\text { /Ser: } \text { disfórico: } \text { culpabilidad }}$

Esta descripción de rigurosa simetría antitética se encuentra engastada en una antítesis textual explícita más amplia, igualmente rigurosa y no menos simétrica:

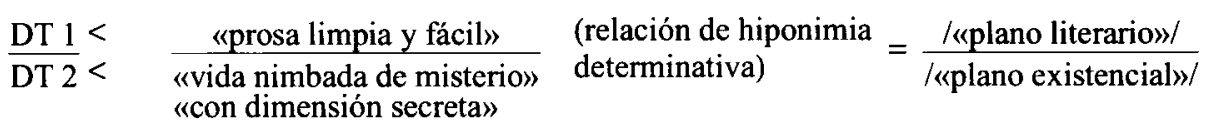

Y si ahora reunimos los términos últimos del proceso, eliminando los vocablos literales que constituyen el ropaje estilístico del texto, se nos revela la siguiente equivalencia:

$$
\frac{/ \text { plano literario/ }}{/ \text { plano existencial/ }}=\frac{/ \text { Parecer: eufórico: inocencia/ }}{\text { /Ser: disfórico: culpabilidad/ }}
$$

Los resultados hablan por sí mismos: el texto, partiendo del fraccionamiento de la literatura del S1 en una forma eufórica y un fondo disfórico, 
acaba por recalcar el vínculo probable entre ese fondo literario disfórico y una dimensión existencial disfórica, vivida y no ya representada (literaturizada) de la que aquél se diría emanar. Pero, además: las secuencias textuales que ponen en escena el Objeto del PN 2, a diferencia de las que describían el conjunto del PN 1 de uso, ya no están modalizadas según el /parecer/, sino de acuerdo con el /ser/: las opiniones tanto sobre la forma de la literatura del S1 como sobre su fondo son juicios y no meras hipótesis: el Sujeto Enunciador afirma sin sombra de duda que la primera era risueña y el segundo violento e irracional, por mucho que a la vez siembre el texto de vocablos inciertos que pudieran llamar a engaño a un lector ingenuo, haciéndole creer que se contenta con enunciar consideraciones probables: así, el SE habla de la «apariencia» para referirse a la forma literaria, pero eso no significa que la forma «risueña» sea sólo aparente; y sostiene que la "dimensión secreta de la vida misteriosa» del S1 «parecia ser la fuente de ese fondo inquietante, irracional y violento que transparecia a veces en su textos, aun los más juguetones y risueños», sin que tan sospechosa reduplicación del verbo ponga en tela de juicio lo muy real de la violencia, la irracionalidad y la inquietud subyacentes, que son establecidas en sí mismas como hechos incontestables. Es en la equívoca atribución de tales hechos irrecusables al plano literario y/o al plano existencial donde estriba la eficacia del funcionamiento retórico de este doble enunciado.

9. El Destinatario o Beneficiario del PN 2 asume trazos difusos cuando asoma en la SC 8; allí la obra literaria del S1 alcanza el telos que la preside desde su nacimiento:

Obra literaria de imaginación

1. Abrir puertas inéditas

2. Mostrar fondos desconocidos de la condición humana

3. Rozar lo trascendente

Las tres imágenes, espaciales, se orientan a plasmar una profundidad abismática e imprecisa; el S1 está siendo descrito como héroe de la experiencia interior (las SC 7 y 13, recordémoslo, establecían para el S1 la homologación /espacio existencial $=$ interior $=$ literatura/). Al implantar esta isotopía de la /interioridad/, a la que corresponde el nuevo rol temático del S1 como /explorador íntimo/, el texto reactualiza el mito agustiniano de la introyección de la trascendencia; y la literatura queda situada por la expresión "rozar lo trascendente» en las lindes de lo inefable, en el ámbito de la experiencia mística. El Destinatario del PN 2 /realización artística/ es, por tanto, una suerte de /conocimiento metafisico/.

10. Pero entre el Objeto /temas fantásticos/y su Destinatario /conocimiento metafísico/ media una gran distancia, la que separa la literatura de imaginación de la vivencia cuasi-mística. Esta distancia sólo puede salvarse gracias a un método (a una vía) que, el texto no deja lugar a vacilaciones, es el /juego/, nuevo recorrido figurativo pergeñado en dos tiempos paradigmáticamente unidos: 
SC 6: Actividades lúdicas del S1: recogida de «noticias insólitas»; construcción de «objetos inverosímiles»; práctica de la trompeta; exploración de un París «secreto y mágico»; asistencia a un «congreso de brujas». Notas semánticas que las definen: /irrealismo/ y /carácter taumatúrgico/. Consecuencia: el juego vital del S1 desrealiza y vuelve esotérico su universo privado.

SC 8: Vinculación del /juego/ del S1 con el Objeto /literatura/ de su $P N 2$ principal. La irrealidad lúdica deviene «instrumento de creación y exploración artística útil y provechoso»r.

Para él, a) escribir era jugar, divertirse, organizar la vida - las palabras, las ideas(definición de la escritura) b) con la arbitrariedad, la libertad, la fantasia y la irresponsabilidad (calificaciones modales a ella aplicadas) c) de los niños o los locos (sujeto de la escritura y de sus calificaciones)

a) Núcleo germinal de la definición: equivalencia jugar = organizar la vida, que es en puridad la categoría hiperonimica dominante en torno a la que giran, como adyacentes explicativos parasinónimos, los demás términos del enunciado:

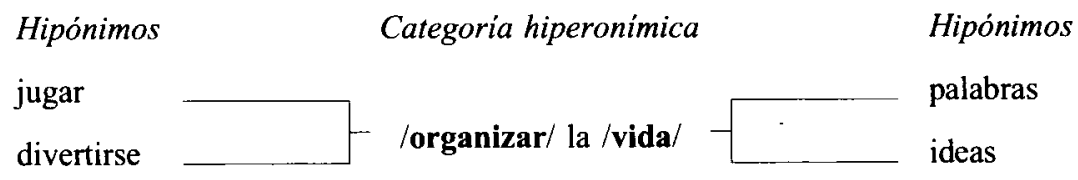

$\mathrm{Si}$ /organizar/ es la categoría, y /jugar + divertirse/ el polo retenido por el texto, la dialéctica aserción/negación, constitutiva de toda relación significante - según el principio estructural - convoca por necesidad la imagen ausente del polo negado pero imprescindible para el funcionamiento semántico de la categoría: /organizar/ = /jugar + divertirse vs. $x /$. ¿Qué es $x$, el término semánticamente opuesto a los parasinónimos jugar + divertirse? No puede ser sino otro par de verbos marcados por semas contrarios, verbos dificiles de precisar, pero susceptibles de parafrasearse en la expresión tradicional «esto no es un juego». Al escoger tan sólo uno de los términos de la categoría y dejar el otro en una oscuridad elusiva ${ }^{3}$, la definición del escribir como organizar y del organizar como jugar elimina del campo de maniobra literario del S1 todo lo que no es juego ni divertimento: todo lo serio. $\mathrm{Y}$ sucede exactamente lo mismo con la categoria /vida/ $=$ /palabras + ideas vs. $x /$; de la dimensión existencial del S1 es expulsado también

${ }^{3}$ El discurso elusivo es aquel que enfatiza uno sólo de los términos de la relación significante, pero que lo que hace con el propósito de subrayar más fuertemente la ausencia de su contrario-complementario. Vid. Coquet (1973: 129). 
cuanto no son palabras ni ideas: todas las cosas, todos los referentes no imaginarios.

b) Luego la calificación modal de este proceso no viene sino a enfatizarlo de forma redundante: en efecto, un ludos literario sin objeto externo, un esparcimiento sin referente es por definición «arbitrario, libre, fastástico, irresponsable».

c) $\mathrm{Y}$ todas ellas son propiedades de los simples de este mundo, en los que reside, como es bien sabido, una suerte de peligrosa inocencia: los «niños»y los «locos».

$\mathrm{La}$ actividad literaria descrita en estos términos se impone al lector como el vivo contra-modelo de toda literatura comprometida; y el PN 2 /realización artística/, globalmente considerado, acaba siendo un anti-programa del tercer y último programa por venir, al que llamaremos /realización social/.

11. Recapitulando el PN 2: el universo íntimo del S1 tiene una tonalidad esotérica y pueril; de ahí que la búsqueda agustiniana de la trascendencia adopte el ambiguo aspecto de un genuino descensus ad inferos: brotada en un suelo violento y alcanzada por medio de un juego equívoco, a medio camino entre la aún-no-razón (infancia) y la sin-razón (locura), juego que se sirve de lo literario para sus fines, dicha búsqueda tiende hacia un conocimiento metafisico ambivalente, considerado como tal por el SE, del que está excluida la realidad inmediata: lo serio, lo importante. El retrato del S1 lo presenta como actor ensimismado, que pese a conservar su rol de /amigo admirable/ y su competencia /ético-social/ ( $\mathrm{SC} \mathrm{6)} \mathrm{se} \mathrm{enreda} \mathrm{en} \mathrm{un} \mathrm{mundo} \mathrm{ilusorio} \mathrm{que} \mathrm{él}$ mismo ha construido (tal ensimismamiento se irá intensificando poco a poco, y en la misma medida disminuirá la competencia ético-social del S1). El juego vivido y literario es para él a la vez herramienta y rehabilitación; ahora bien, el tratamiento estético de lo irracional absorbe todas las posibilidades creativas de la escritura del S1, incapaz de sobrepasar los límites de su brumoso horizonte metafísico. Y, además, esta conquista del arte y la salud tiene como requisito la ayuda recibida por el S1 de un co-Sujeto 2 que, siendo su igual sobre el plano de la existencia, se le somete en el nivel de la práctica literaria. Sólo el mantenimiento de esta injusta relación distributiva permite al S1 realizar su dificil síntesis entre culpabilidad e inocencia, entre instinto oscuro y placer estético ${ }^{4}$. Esquema final del PN 2 /realización artística/ ${ }^{5}$ :

${ }^{4}$ El que el S1 pudiera ser anterior ya antes de integrarse en el PN 1 resulta irrelevante para el texto, preocupado por reflejar la etapa sincrónica que comprende los PN 1 y 2 y el período posterior correspondiente al PN 3.

${ }^{5}$ Quedan fuera de este esquema, por razones de espacio, jerarquía y claridad las modificaciones que se registran tras el cambio de programas narrativos en el sistema actancial completo, y que ya hemos mencionado en el epígrafe 7. 
PN 2

SUJETO 1

Destinador: S1

Roles

Competencias

Sujeto: S1

Destinatario: conocimiento metafísico

sujeto lúdico

psicológica

Recorrido fig.: juego

creador literario

cognoscitiva

Operador: escritura literaria

explorador interior

psic. cogn.

Objeto: lit. de imaginación

amigo admirable

ético-social

12. Con la SC 9 llega el momento de la gran crisis narrativa de $L a$ trompeta de Deyá. Lo restante del texto estará destinado a aclarar los términos de lo que esta secuencia designa como la «mutación»-PN 3- del S1. Para el analista, el foco de atención por excelencia se hallará en el sutil encaje de supresiones, adiciones y modificaciones que el anunciado PN 3 tramará sobre el cañamazo empleado por el relato - provisto de una muy notable memoria paradigmática- para urdir los PN 1 y 2.

13. El elemento determinante del PN 3 es su Objeto, doble o bifronte: /literatura/ y/o /revolución/. En la imposible concordia de su naturaleza dual - pese al hipotético agente de síntesis que el texto propone, la /imaginación/-, estribará precisamente el fracaso narrativo, la ausencia de sanción, de este último PN.

El Objeto /literatura/ del PN 1 y 2 sufre en el PN 3 un deterioro a la par cuantitativo - pasa de Objeto único a co-Objeto del nuevo Objeto /revolución/ - y cualitativo - pues ve alteradas en profundidad sus anteriores propiedades por la nueva teleología del S1: Objeto virtual ( $h a-$ blado) en el PN 1, Objeto realizado en el PN 2 (obra de imaginación), la /literatura/ es degradada en el PN 3 al hipónimo "hojas volanderas» (SC 9) y a «una obra dispersa en la circunstancia y la actualidad» (SC 10), con lo que se introduce una fuerte antítesis temporal-aspectual sobre el parámetro duratividad/puntualidad: obra literaria antropológicamente densa y perdurable en PN 1 y 2 frente a la enfatizada transitoriedad de la escrita en el PN 3.

E1 objeto subordinante /revolución/, ente negativo y futuro, es apenas materia de tímidas alusiones en el texto, que parece emplazar un capcioso término de unión entre él y el co-Objeto /literatura/. Efectivamente, si es válida nuestra paráfrasis previa «temas fantásticos» $=/ 1$ iteratura de imaginación/, entonces, considerando que el texto expande literalmente el lexema «revolución» en la ya tópica elipsis «imaginación al poder» (SC 9), hay implícita en la descripción de ambos Objetos una estructura léxica ternaria: 


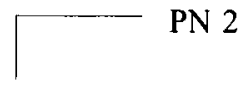

A

literatura
PN 2

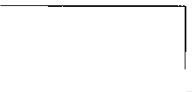

B
PN 3

$\mathrm{C}$

poder

La combinación $\mathrm{AB}$ define al PN 2; la combinación BC, al PN 3. Se diría que en la estructura textual de superficie el término $B$, la «imaginación') funciona como enlace entre los términos $\mathrm{AC}$, literatura y poder, pero no está ahí sino para señalar la imposibilidad de tal función mediadora («imaginación al poder» figura encerrado entre irónicas comillas). El texto acepta, y valoriza, la asociación $\mathrm{AB}$, pero no la $\mathrm{BC}$ (aunque para demostrarlo tendremos que esperar al análisis de las relaciones entre el SE y el PN 3) y por consiguiente tampoco la AC, cuyos términos están radicalmente alejados entre sí y resultan incompatibles: la engañosa estructura léxica superficial ternaria es en realidad una oposición binaria no dialéctica: (literatura-imaginación) vs poder. Con ello se aclara el que el PN 2 /realización artística/ sea un anti-programa de toda literatura comprometida si por tal hay que entender aquella que aspira a ejercer un poder transformador sobre la realidad social. Así pues, la literatura imaginativa del S1 queda recluida en el ámbito de la búsqueda metafísica, siendo considerado por el texto como vano o ilusorio todo intento de enraizar ese acto artístico en el suelo concreto de lo real. Y cuando el S1 persevera en su propósito de unir la praxis literaria a la praxis política, el SE rebaja el estatuto cualitativo de la literatura por él escrita al de un simple panfleto, y acaba sumergiéndola bajo un poco halagüeño enjuiciamiento global: «Este otro Julio Cortázar, me parece, fue menos personal y creador como escritor que el primigenio». (SC 13) Y un pequeño detalle complementario: en la SC 2 el lazo del Sujeto doble con la /literatura/ se había calificado de «compromiso exclusivo, excluyente y total». La saturación afectiva, lograda mediante la hipérbole y el políptoton, del significado del "compromiso» originario no puede dejar de acarrear por implicación semántica la idea de traición (rompimiento de un pacto moral anterior) en el tránsito desde el PN 1 y 2 hasta el PN 3.

En resumidas cuentas, el PN 3 fracasa, entre otras cosas, porque aspira a realizar una síntesis, que el texto juzga impracticable e indeseable desde sus presupuestos semi-implícitos, entre dos esferas de la realidad, la artística y la política. Al operador que esta voluntad pone en juego lo llamaremos /escritura militante/; y ni que decir tiene que el Destinatario final del proceso ya no puede ser ningún tipo de conocimiento metafísico, positivo o negativo, sino más llanamente una /transformación social/.

14. En la persecución de sus nuevos objetivos el S1 pasa por una serie de cambios exteriores:

En los PN 1 y 2 el Sujeto Enunciador y el Sujeto Focalizador del texto coincidían sistemáticamente; en el PN 3, el SE intercala entre él 
mismo y el S1 un centro de visión indefinido y plural: «Se lo vio entonces en las barricadas de París [...]» (SC 10). Este distanciamiento actorial tiene como correlato una mudanza significativa en la definición topológica del S1: apegado a la /interioridad/ en los PN 1 y 2, el S1 se entrega a una frenética tarea viajera y política en el PN 3; de intima, su vida deviene casi "promiscua», marcada por el rasgo espacial contrario /exterioridad/. En consonancia con lo cual, al recorrido figurativo /diálogo privado/ de los PN 1 y 2 responde en el PN 3 otro que podemos llamar /conversación militante/.

Los cambios en la prosopografia del personaje son aún más notables: PN 1y 2: «muchacho de cabellos cortísimos-lampiño» (SC 2-5) - PN 3 "se había dejado crecer el cabello-tenía unas barbas rojizas e imponentes, de profeta bíblico» (SC 12). Inútil insistir sobre las connotaciones culturales de rasgos tan intensamente semiotizados: «barba roja» = peligro; «profeta bíblico»=anunciador visionario de grandes cataclismos provocados por el pecado.

La finalidad perseguida por el S1 con semejante muda de piel y trastrueque de costumbres es integrarse en ese otro Sujeto Colectivo de la historia revolucionaria en ciernes. ¿Logra el S1 cumplir este sub-programa? El SE, que en la exposición del PN 3 procura eludir siempre que puede todo veredicto negativo demasiado explícito, se limita a yuxtaponer contrastes como al desgaire, confiando en la complicidad enciclopédica de su lector: «Se lo vio [...] confundido con los estudiantes que querian llevar "la imaginación al poder". Tenía cincuenta y cuatro años».

15. Los cambios exteriores se completan con otros más fundamentales: el S1 reasume y modifica a la vez la definición de su /hacer/, esto es, su posición en el sistema de roles-competencias, operación que señala tanto la lógica como las debilidades del nuevo programa. Conserva en su integridad el rol de /sujeto lúdico/ (SC 10,12,13), y parece también mantener, aunque con muchas restricciones, el rol de /amigo admirable/ (SC 10, 12). En cambio, se le adjudica pleonásticamente un rol inédito, /intelectual revolucionario/, trasformación de los previos /intelectual brillante/ y /creador literario/: «Los 16 (años) que le faltaban por vivir sería el escritor comprometido con el socialismo, el defensor de Cuba y Nicaragua, el firmante de manifiestos y el habitué de congresos revolucionarios que fue hasta el final» (SC 9). En esquema:

PN 1 ROLES

PN 2

pareja ideal intelec. brillantes amigos adm. sujeto lúdico creador lit. amigo adm. explorador inter.

\section{PN 3}

sujeto lúdico intelec. revoluc. amigo adm.
COMPETENCIAS

psicológica cognoscitiva ético-social psico.-cognos. 
La regularidad de la tabla cela empero el hecho de que todos los pares rol-competencia pasan por ciertas alteraciones que pueden expresarse con un solo semema: /empeoramiento/. Así, perjudica al par /amigo admirable/-/ético social/ la intensificación de las tendencias introvertidas del S1 y el distanciamiento con respecto a él del SE; y el rol doble /sujeto lúdico-pareja ideal/-/competencia psicológica/ se desequilibra tras el cambio de pareja por el S1 (SC 12), que el SE liga negativamente a las alteraciones prosopográficas del $\mathrm{S} 1$. Lo cual indica que, si bien perdura en el PN 3 el rol /sujeto lúdico/ y su recorrido figurativo concomitante /juego/, con la inevitable actualización en ese mismo programa de su consecuencia, el carácter irreal, esotérico y pueril del mundo íntimo del S1, ello sucede sin que el $\mathrm{S} 1$ posea ya los medios para controlarlo - el apoyo terapéutico del S2 y del arte-, y justo en el momento en el que el S1 ambiciona consagrarse a la actividad exterior seria e importante por excelencia, la política: PN 2, SC 8: Escribir=jugar=organizar la vida - - - PN 3, SC: 10 Militar $=\mathrm{x}=$ organizar la vida. Al S1 lo lastra la ley de la inalterabilidad del carácter, que lo vuelve inútil para trabajar fuera del territorio privado del ego. «Revistas eróticas», «marihuana», «revolución» sustituyen ahora al «jazz» y a los «fantasmas», marcando el tránsito lúdico del S1 desde la alta cultura a la cultura underground. En semejante sistema de desdichas semióticas, la insistencia del SE en el «rejuvenecimiento» del S1 no hace sino reforzar el efecto de infantilización que lo envuelve: SC 12: «[...] incluso cabría decir que se había vuelto más fresco y juvenil, pero costaba trabajo relacionarlo con el de antes»; SC 13: «[...] todas las veces que yo lo vi me pareció joven, exaltado, dispuesto».

Pero el rol-competencia que más sufre del cambio de PN es el de /intelectual brillante/-/creador literario/. El SE niega al S1, de forma tajante, toda competencia cognoscitiva para cumplir su nuevo programa:

a) Como en la primera, aunque de una manera distinta, en esta segunda etapa de su vida, dio más de lo que recibió, b) y aunque creo que se equivocó muchas veces - como aquella en que afirmó que todos los crimenes del estalinismo eran un mero accident de parcours del comunismo-, $\mathrm{c}$ ) incluso en esas equivocaciones había tan mànifiestas inocencia e ingenuidad que era dificil perderle el respeto.

Punto clave de las diferencias entre programas: las habilidades culturales y los conocimientos trascendentales del S1 en los PN 1 y 2 , una vez perdido por aquél el delicado equilibrio matrimonial y psicológico que los hacía posibles, fracasan estrepitosamente cuando se trata de ejercitarlos no ya dentro del abismo insondable de la eterna condición humana, sino sobre la materia misma de la realidad histórica y política contemporánea. 
Por cierto, la alusión del citado fragmento a las atrocidades estalinianas dista mucho de ser textualmente gratuita; explosión histórica de irracionalidad y de violencia, los crímenes comunistas están en el texto paradigmáticamente ligados al fondo existencial disfórico, irracional y violento, que el S1 lograba exorcizar gracias a su arte literario en los PN 1 y 2. Abandonados los higiénicos senderos de estos programas, el $\mathrm{S} 1$ cede a sí mismo y su potencial crueldad acaba volviéndole cómplice voluntario por consintiente de una masacre. Eso sí: al igual que en el pasado la zona ominosa de la etopeya del S1 aparecía disimulada entre las amables formas de su jugueteo vital, aquí también la semilla de la violencia se incardina entre dos reactualizaciones de: a) la competencia ético-social («dio más de lo que recibió»); y b) la irresponsable puerilidad («sus manifiestas inocencia e ingenuidad») del S1. Júzguese la intención de tal entreveramiento de referencias estereotipadas al Bien -el candor de la infancia-y al Mal bajo su aspecto más tenebroso - el asesinato tecnologizado y sistemático.

Por último, el rol /explorador interior/ del PN 2 desaparece de raíz, puesto que contradice la topología exterior del rol /intelectual revolucionario/; y su pérdida marca el momento exacto en el que el S1 comienza a cometer esos muchos errores de bulto que para el SE nos abren las puertas de su alma.

PN 3 realización política

SUJETO 1

Destinador: S1

Sujeto: S1

Destinatario: transformac. social

Recor. fig: declaración pública + juego

Operador: conversación militante + escritura militante

Objeto: revolución + literatura
Roles

Competencias

sujeto lúdico

intelectual revol.

amigo admirable psicológica

cognoscitiva

ético-social

16. ¿Cuáles son las razones de esta metamorfosis? El SE se dispone ahora a reescribir, contra la versión oficial, refrendada por el propio $\mathrm{S} 1$ en el pasado (SC 9), la biografía del S1.

El S1, autodestinado y libre durante los PN 1 y 2, parece continuar siéndolo en el PN 3: la SC 10 reabsorbe en el S1 los motivos de su giro copernicano personal, atribuyendo a éste una causa «ética». Ahora bien, la primera matización lateral de tal supuesto consistirá en hacer retroceder en el tiempo el dato etiológico del cambio del S1, dato que ya no es la revuelta estudiantil, sino, precisamente, la quiebra del PN 1 /realización matrimonial/y de todo lo que éste conlleva (una deleitosa felicidad privada en torno a los santuarios de la alta cultura y a los paraísos perdidos: «museos», «templos», «iglesias ortodoxas», «restaurantes de la Acrópolis», «la islita de Hydra») (SC 11). Desaparecido para él dicho enclave de felicidad in- 
temporal, el S1 se hunde en los conflictos de la historia. El lector no sabrá nunca cuál fue la causa de la expulsión del Sl de su pequeño jardín de las delicias, pero no le queda más remedio que estar seguro de lo mismo de lo que lo está el SE: fuese cual fuese aquélla, la expulsión determinó la metamorfosis del S1.

\author{
Causa $1 .^{\mathrm{a}} \quad\left[x ? \Rightarrow\right.$ Consecuencias $1 .^{\mathrm{a}}$ ruptura $P N I$ \\ Caus. $2 .^{\circ}$ ruptura $P N 1 \Rightarrow$ Consec $2 .^{\text {a. }}$ ruptura PN 2 \\ Caus. 3. ${ }^{\text {a }}$ : ruptura $P N 2 \Rightarrow \begin{aligned} & \text { Consc } 33^{\circ} \text { : - } \\ & \text { asunción } P N\end{aligned}$
}

Lo que pone en evidencia que bajo la nebulosa teleología privada llamada «ética» yace en el texto una razón primera que menoscaba la «ética» al rango de mera razón segunda; esto es, de racionalización. El SE despacha así los motivos de orden social y objetivo para la «mutación» en beneficio del énfasis puesto sobre la subjetividad dañada como catalizador, reproduciendo con ello un argumento retórico-político clásico: todo impulso revolucionario se debería en última instancia a un desarreglo íntimo de la propia conciencia. Y ello lo confirma el que el SE afirme sin sombra de duda: «el cambio de Julio fue mucho más profundo y abarcador que el de la acción política» (SC 11), declaración que da por sentado un orden de prelación entre las esferas de lo individual (jerárquicamente superior) y de lo político (jerárquicamente inferior): el hombre es algo que sobrepasa, que trasciende su dimensión política tanto hacia dentro "profundo" = /interio$\mathrm{ridad} /$ - como hacia afuera - «abarcador» = englobante. Ésa es la hondura humana en la que se gestan las grandes metamorfosis del individuo; las circunstacias históricas concretas resultan en comparación, para el SE, meros epifenómenos. SE y S1 separan aquí sus caminos; el SE explora y juzga el PN 3 del S1 de acuerdo con una variante extremada de la teoría individualista, cuyo núcleo está formado por la ideología matrimonial - de ahí el tácito post hoc ergo propter hoc que convierte a la separación del Sujeto doble en causa de la metamorfosis del $\mathrm{S} 1-$, y renuncia a seguirle en su adopción de un sistema axiológico de tipo colectivo-político, inverso al que le guiaba en los PN 1 y 2 (vida privada y literaria intensa y fascinante, acción política nula); la simpatía del SE por el nuevo programa del S1 es inexistente, lo que marca los límites intelectuales y valorativos de este recuerdo.

17. Porque la reescritura de la biografía del $\mathrm{S} 1$ es un proceso de valoración por parte del $\mathrm{SE}$, a pesar y contra todos los aspavientos de prudencia en que el SE se complace. Éste ha escogido desde el inicio del texto un nivel de pertinencia primario para su decurso: el compartido oficio de la escritura que lo emparenta al S1. Sin embargo, una triple distancia los aleja: distancia espacial - sus contactos son esporádicos y en puntos distintos del planeta (SC 2 y 12); distancia temporal - sus encuentros son ocasionales-; y distancia psicológica: el ensimismamiento del S1 llega a 
rozar el hermetismo, lo que obliga al SE a tildar de «amistad sin intimidad» su relación con el S1 (SC 7). Piénsese en lo ambiguo de la latente y no siempre actualizada competencia /ético-social/ de éste; el S1 sojuzga al S2 en beneficio propio durante los PN 1 y 2 , y coarta la libre espontaneidad de sus amigos «bajo un sistema de reglas a las que había que someterse para conservar su amistad», coerción que el texto, aun ligándola también al «encanto del personaje», vincula con la culpable dimensión secreta de la vida del S1 (SC 7).

Resultado de este alejamiento es el recorte, pero también la objetivación, del alcance testimonial del recuerdo del SE. La diferencia entre ambos se hace máxima en el PN 3, acompañada por una inversión de los respectivos roles mutuos: en los PN 1 y 2 el Sl actuaba como distanciador psicológico del SE, que le estaba sometido por sentimientos de «admiración», «envidia», «deslumbramiento», «fascinación», mientras que en el PN 3 es el SE quien hace las veces de distanciador ideológico del S1, puesto que, sin dejar de mentar la continuidad de los lazos amistosos que a él lo unen, rebaja todas sus competencias y llega hasta afirmar que pese a los numerosos errores de aquél, «era dificil perderle el respeto. Yo no se lo perdi nunca, ni tampoco el cariño y la amistad que - aunque a la distanciasobrevivieron a todas nuestras discrepancias políticas». «No perder el respeto» indica aquí tan sólo que bien hubiera podido perdérselo, de no beneficiar el S1 del crédito adquirido en sus anteriores programas exitosos; y así si los PN 1 y 2 /realización conyugal/ y /realización artística/ manifiestan la supremacía del S1 sobre el SE, el PN 3 /realización política/ subvierte los términos de esta ecuación intersubjetiva.

Poco sorprenderá el mencionado fenómeno si se repara en que los tres programas del $\mathrm{S} 1$ aparecen axiológicamente juzgados, desde antes de su misma exposición textual, mediante un sistema de catáforas:

(SC I) [...] a) me alegró mucho saber que Aurora había estado a su lado en estos últimos meses b) y que, gracias a ella, tuvo un entierro sobrio, sin las previsibles payasadas de los cuervos revolucionarios.

a) Catáfora 1. ${ }^{a}$, eufórica : reinstala, en el final del trayecto biográfico del S1, a su co-Sujeto durante el PN 1 y Ayudante en el 2, programas reactualizados por ello a su vez, con lo que se elimina tácitamente el PN 3. Idéntica anulación se produce cuando, en la última secuencia del texto (14), el SE, so capa de emotivo recuerdo final, recrea ante el lector la imagen del primitivo $\mathrm{S} 1$ :

De rato en rato oigo desafinar una trompeta. No hay nadie por los alrededores. El sonido sale, pues, de ese cartel del fondo de la sala, donde un chiquillo larguirucho y lampiño, con el pelo cortado a lo alemán y una camiseta de mangas cortas - el Julio Cortázar que yo conocí- juega a su juego favorito. 
devolviéndole, uno a uno, todos los aparejos de su universo original: el /encierro/, el /juego/, la /magia/ y hasta su mismo aspecto físico. El intervalo - el PN 3 - queda así simbólicamente aniquilado por la ternura soberana de la memoria del amigo. A diferencia de los PN 1 y 2, no hay para él sanción posible.

b) Catáfora $2 .^{a}$, disfórica: efectúa, de forma sintética y a través de un léxico depreciativo, una impugnación axiológica del contenido del PN 3 («previsibles payasadas de los cuervos revolucionarios»)

Todo estaba claro, por consiguiente, desde el principio. Pero había que contarlo con visos de objetividad; de ahí que el texto parezca a primera vista menos elíptico y alusivo de lo que en verdad es. Veáse para muestra el modo en que el SE se remite modestamente al saber interpretativo último del S2: sobre el S2, ordenado, pulcro, vital (SC 4 y 14), agente compensador, a lo largo de la entera evocación, de las unilaterales inclinaciones del S1, recae la entera responsabilidad del enjuiciamiento de la biografía del $\mathrm{S} 1$, mientras que el SE se satisface con bordar cautas y prudentes variaciones en torno a la indecidibilidad de toda existencia (SC 13-14):

Este otro Julio Cortázar, me parece, fue menos personal y creador como escritor que el primigenio. Pero tengo la sospecha de que, compensatoriamente, tuvo una vida más intensa, $\mathrm{y}$, acaso, más feliz que aquella de antes, en la que, como dijo, la existencia se resumía para él en un libro (...) Si alguien lo sabe debe ser Aurora, por supuesto. Yo no cometo la imprudencia de preguntárselo.

Primero: si la vida del S1 en el PN 3 se modela de acuerdo con la actividad política, entonces el texto impone aquí una relación inversamente proporcional entre los PN 1-2 y 3: a mayor /realización política/ menor/realización artística/ (literatura y poder son para el SE esferas antagónicas). Segundo: el combate político proporciona al S1 una vida «intensa y feliz»: pero, dado que era la dimensión existencial del S1 la que aparecía gravada desde el comienzo por una profunda violencia e irracionalidad, en el curso del PN 3 el fondo oscuro, la /culpabilidad/ del S1 se enseñorea de toda su experiencia, en tanto que es relegado al olvido el brillante conjuro terapéutico del arte.

$$
\frac{\text { Éxito }}{\text { Fracaso }}=\frac{\text { plano existencia }}{\text { plano artístico }}=\frac{/ \text { culpabilidad } /}{\text { /inocencia } /}
$$

Sin embargo, el SE declara inmediatamente después: «Si alguien lo sabe, debe ser Aurora, por supuesto. Yo no cometo la impertinencia de preguntárselo». Semejante ademán de respetuoso pudor vela exactamente el mismo recurso de espuria proyección que hemos visto operar en el momento de convertir al S1 en un Sujeto egoísta y despótico en relación con el S2 durante el PN 2: se pretende, mediante una estrategia retórica, el sancionamiento cómplice por parte del S2 de una interpretación retrospectiva que en buena ley tan sólo ofrece como garantía el conocimiento externo 
del propio SE, sin que en ningún caso se citen palabras literales del S2; y ello en el mismo instante en que se simula reconocer a éste el derecho de recusar dicha reescritura biográfica. Pero, ¿cómo podría llevarse a efecto tal recusación, si el recato del SE le prohíbe - "sería una impertinencia»todo intento de verificar su discurso en la única fuente autorizada para ese menester? Pero esta manipulatoria discreción superficial no impide que en el texto se deslicen contundentes juicios de valor, incluso si no aparecen allí donde el lector los espera. Obsérvese el modo en que se figurativiza, por dos veces, la metamorfosis del S1:

(SC 9). El cambio de Cortázar - el más extraordinario que me haya tocado ver nunca en ser alguno, una mutación que muchas veces se me ocurrió comparar con la que experimenta el narrador de ese relato suyo, Axolotl, en que aquél se transforma en el pececillo que está observando [...]

La descripción del cambio discurre sobre el nivel de pertinencia escritura escogido por el texto, ganando así en coherencia: se emplea un ejemplo extraído de la obra literaria del mismo $\mathrm{S} 1$ como modelo. Pero este ejemplo lleva implícitos: a) la regresión del S1 en el orden evolutivo animal: de ser humano a pez; b) la disminución de jerarquía gramatical: de sustantivo positivo a diminutivo: «pececillo»; c) la actualización de un nutrido número de connotaciones culturales: /encierro/-/pérdida de libertad/-/esclavitud/; /movimiento circular/-/actividad sin sentido/-; /objeto exótico/-/objeto de contemplación/-/objeto de asombro/-/objeto de burla/.

(SC 12) (...) ¿Era él? ¿Era Julio Cortázar? Desde luego que lo era, pero como el gusanito que se volvió mariposa o el fakir del cuento que luego de soñar con maharajás, abrió los ojos y estaba sentado en un trono, rodeado de cortesanos que le rendían pleitesía.

Las dos comparaciones parecen positivas, meliorativas. ¿Lo son de verdad? El gusano que eclosiona se convierte en bella mariposa, es cierto, pero la mariposa es en nuestro universo cultural un prestigioso /objeto venatorio y coleccionable/ (recordemos los "cuervos revolucionarios" de la SC 1), además de símbolo zoológico de un /ser frágil/ y de un /hacer voluble/. En cuanto al fakir convertido en cortesano, amén de representar el primero el /ascetismo/ y la /espiritualidad/frente a la /molicie/ y a la /mundanidad/ del segundo, los «cortesanos» que lo rodean (recuérdese que los «cuervos revolucionarios» hacen «previsibles payasadas») son la quintaesencia del /servilismo/ y de la /mendacidad/ (bufones?), a lo que hay que añadir la índole alucinatoria de la transformación: «luego de soñar con maharajás...» 
18. ¿Cabe aún, por tanto, hablar de inquietud ética y de Sujeto autodestinado para referirse al avatar biográfico del S1? Detrás de su metamorfosis, detrás del cambio de programas cuya explicación y valoración constituyen el entero discurso del texto, se diría que no hay sino una pura necesidad de orden psicológico: fracasada su primera etapa, destruido su gozoso statu quo primigenio, al S1 no le queda más opción que buscar otros exutorios para su culpabilidad existencial; una pequeña manipulación por parte de los "cuervos revolucionarios» y el S1 hallará en la lucha política el remedio más adecuado a la reviviscencia, ocasionada por la quiebra de su matrimonio y del universo estético que lo envolvía, de sus monstruos interiores. Este recuerdo escenifica en el S1 una memoria freudiana que se ignora: el retorno a la conciencia de lo reprimido no puede eludirse, una vez derruidas las barreras que lo mantenían sojuzgado. Nada hay de progresivo en el cambio del Si, pero sí mucho de regresivo: pierde lo bueno que tuvo, se multiplica lo malo de lo que nunca dejó de padecer. El S1, al final, no era tan excelente amigo como parecía, ni su inteligencia brillaba tanto como parecía, ni su juego resultaba tan inocente como parecía. Soterrada en todo ello dormitaba una semilla del diablo. Y el diablo es feo: curioso que lo único que sí se altera realmente en el S1 sea su aspecto físico y algunas de sus costumbres. No extraña entonces que el SE sienta escasa simpatía por la última etapa de la existencia de su amigo, cuya paradoja y derrota ha sabido contarnos con tan modesta elocuencia.

\section{APÉNDICE: LA TROMPETA DE DEYÁ}

\section{Mario Vargas Llosa}

(El Pais, domingo 28 de julio de 1991)

1. Aquel domingo de 1984 acababa de instalarme en mi escritorio para escribir un artículo, cuando sonó el teléfono. Hice algo que ya entonces no hacía nunca: levantar el auricular. «Julio Cortázar ha muerto» —ordenó la voz- «Dícteme su comentario».

Pensé en un verso de Vallejo — «spañol de puro bestia»- y, balbuceando, le obedecí. Pero aquel domingo, en vez de escribir el artículo, me quedé hojeando y releyendo alguno de sus cuentos y páginas de sus novelas que mi memoria conservaba muy vivos. Hacía tiempo que no sabía nada de él. No sospechaba ni su larga enfermedad ni su dolorosa agonía. Pero me alegró mucho saber que Aurora había estado a su lado en estos últimos meses y que, gracias a ella, tuvo un entierro sobrio, sin las previsibles payasadas de los cuervos revolucionarios.

2. Los había conocido a ambos un cuarto de siglo atrás, en casa de un amigo común, en París, y desde entonces, hasta la última vez que los vi juntos, en 1967, en Grecia - donde oficiábamos de traductores, en una conferencia internacional 
sobre algodón - nunca dejé de maravillarme con el espectáculo que significaba ver y oír conversar a Aurora y Julio, en tándem. Todos los demás parecíamos sobrar. Todo lo que decían era inteligente, culto, divertido, vital. Muchas veces pensé: «No pueden ser siempre así. Esas conversaciones las ensayan, en casa, para deslumbrar luego a los interlocutores con las anécdotas inusitadas, las citas brillantísimas, las bromas que, en el momento oportuno, descargan el clima intelectual».

Se pasaban los temas el uno al otro como dos consumados acróbatas y con ellos uno no se aburría nunca. La perfecta complicidad, la secreta inteligencia que parecía unirlos era algo que yo admiraba y envidiaba en la pareja tanto como su simpatía, su compromiso con la literatura - que daba la impresión de ser exclusivo, excluyente y total - y su generosidad para con todo el mundo, y sobre todo, los aprendices como yo.

3. Era difícil determinar quién había leído más y mejor, y cuál de los dos decía cosas más agudas e inesperadas sobre libros y autores. Que Julio escribiera y Aurora sólo tradujera (en su caso ese sólo quiere decir todo lo contrario de lo que parece, claro está) es algo que yo siempre supuse provisional, un transitorio sacrificio de Aurora para que, en la familia, hubiera de momento nada más que un escritor.

4. Ahora que vuelvo a verla, después de tantos años, me muerdo la lengua las dos o tres veces que estoy a punto de preguntarle si tiene muchas cosas escritas, si va a decidirse por fin a publicar... Luce los cabellos grises, pero, en lo demás, es la misma. Pequeña, menuda, con esos grandes ojos azules llenos de inteligencia y la abrumadora vitalidad de antaño. Baja y sube las peñas mallorquinas de Deyá con una agilidad que a mí me deja todo el tiempo rezagado y con palpitaciones. También ella, a su modo, luce aquella virtud cortazariana por excelencia: ser una variante de Dorian Gray.

5. Aquella noche de 1958 me sentaron junto a un muchacho muy alto $y$ delgado, de cabellos cortísimos, lampiño, de grandes manos que movía al hablar. Había publicado ya un librito de cuentos y estaba por publicar una segunda recopilación, en una pequeña colección que dirigía Juan José Arreola, en México. Yo estaba por publicar, también, un libro de relatos y cambiamos experiencias y proyectos, como dos jovencitos que hacen su vela de armas literaria. Sólo al despedirnos me enteré - pasmado- de que era el autor de Bestiario y de tantos textos leídos en la revista de Borges y Victoria Ocampo, Sur, y el admirable traductor de las obras completas de Poe que yo había leído en dos voluminosos tomos publicados por la Universidad de Puerto Rico. Parecía mi contemporáneo, y en realidad era veintidós años mayor que yo.

6. Durante los años sesenta, y, en especial los siete que viví en París, fue uno de mis mejores amigos, y también, algo así como mi modelo y mi mentor. Yo admiraba su vida, sus ritos, sus manías y sus costumbres tanto como la facilidad y la limpieza de su prosa y esa apariencia cotidiana, doméstica y risueña, que en sus cuentos y novelas adoptaban los temas fantásticos. Cada vez que él y Aurora llamaban para invitarme a cenar - al pequeño apartamento vecino a la rue de Sèvres, primero, y luego a la casita en espiral de la rue du Général Beuret- era la fiesta y la felicidad. Me fascinaba ese tablero con recortes de noticias insólitas y los objetos inverosímiles que recogía o fabricaba, y ese recinto misterioso que, 
según la leyenda, existía en su casa, en el que Julio se encerraba a tocar la trompeta y a jugar: el cuarto de los juguetes. Conocía un París secreto y mágico, que no figuraba en guía alguna, y de cada encuentro con él yo salía cargado de tesoros: películas que ver, exposiciones que visitar, rincones por los que merodear, poetas que descubrir y hasta un congreso de brujas en la Mutualité que a mí me aburrió sobremanera pero que él evocaría después, maravillosamente, como un jocoso apocalipsis.

7. Con ese Julio Cortázar era posible ser amigo pero imposible intimar y esa distancia que él sabía imponer, gracias a un sistema de cortesía y de reglas a las que había que someterse para conservar su amistad, era uno de los encantos del personaje: lo nimbaba de cierto misterio, daba a su vida una dimensión secreta que parecía ser la fuente de ese fondo inquietante, irracional y violento, que transparecía a veces en sus textos, aun los más juguetones y risueños. Era un hombre eminentemente privado, con un mundo interior construido y preservado como una obra de arte al que probablemente sólo Aurora tenía acceso, y para el que nada, fuera de la literatura, parecía importar, acaso existir.

8. Esto no significa que fuera libresco, erudito, intelectual, a la manera de un Borges, por ejemplo, que con toda justicia escribió: «Muchas cosas he leído y pocas he vivido». En Julio la literatura parecía disolverse en la experiencia cotidiana e impregnar toda la vida, animándola y enriqueciéndola con un fulgor particular sin privarla de savia, de instinto, de espontaneidad. Probablemente ningún otro escritor dio al juego la dignidad literaria que Cortázar ni hizo del juego un instrumento de creación y exploración artística tan útil y provechoso como él. Pero diciéndolo de este modo tan serio, altero la verdad: porque Julio no jugaba para hacer literatura. Para él escribir era jugar, divertirse, organizar la vida - las palabras, las ideas con la arbitrariedad, la libertad, la fantasía y la irresponsabilidad con que lo hacen los niños o los locos. Pero jugando de este modo la obra de Cortázar abrió puertas inéditas, llegó a mostrar unos fondos desconocidos de la condición humana y a rozar lo trascendente, algo que seguramente él nunca se propuso. No es casual —o más bien sí lo es, pero en ese sentido de «orden de lo casual» que él describió en una de sus ficciones- que la más ambiciosa de sus novelas tuviera como título Rayuela, un juego de niños.

9. El cambio de Cortázar - el más extraordinario que me haya tocado ver nunca en ser alguno, una mutación que muchas veces se me ocurrió comparar con la que experimenta el narrador de ese relato suyo, Axolotl, en que aquél se transforma en el pececillo que está observando - ocurrió, según la versión oficial —que él mismo consagró- en el mayo del 68. Se le vio entonces en las barricadas de París, repartiendo hojas volanderas de su invención, y confundido con los estudiantes que querían llevar «la imaginación al poder». Tenía cincuenta y cuatro años. Los 16 que le faltaban vivir sería el escritor comprometido con el socialismo, el defensor de Cuba y Nicaragua, el firmante de manifiestos y el habitué de congresos revolucionarios que fue hasta el final.

10. En su caso, a diferencia de tantos colegas nuestros que optaron por una militancia semejante pero por esnobismo u oportunismo - un modus vivendi $y$ una manera de escalar posiciones en el establecimiento intelectual, que era y en cierta forma sigue siendo monopolio de la izquierda en el mundo de lengua española-, esta mudanza fue genuina, más dictada por la ética que por la ideología (a la que siguió siendo alérgico) y de una coherencia total. Su vida se organizó en 
función de ella, y se volvió pública, casi promiscua, y su obra se dispersó en la circunstancia y en la actualidad, hasta parecer escrita por otra persona, muy distinta de aquella que, antes, percibía la política como algo muy lejano y con irónico desdén. (Recuerdo la vez que quise presentarle a Juan Goytisolo: «Me abstengo» -bromeó-. "Es demasiado político para mí»). Como en la primera, aunque de una manera distinta, en esta segunda etapa de su vida, dio más de lo que recibió, y aunque creo que se equivocó muchas veces - como aquella en que afirmó que todos los crímenes del estalinismo eran un mero «accident de parcours» del comunismo-, incluso en esas equivocaciones había tan manifiestas inocencia e ingenuidad que era dificil perderle el respeto. Yo no se lo perdí nunca, ni tampoco el cariño y la amistad que - aunque a la distancia - sobrevivieron a todas nuestras discrepancias políticas.

11. Pero el cambio de Julio fue mucho más profundo y abarcador que el de la acción política. Yo estoy seguro de que empezó un año antes del 68, al separarse de Aurora. En 1967, ya lo dije, estuvimos los tres en Grecia, trabajando juntos como traductores. Pasábamos la mañana y la tarde sentados a la misma mesa, en la salä de conferencias del Hilton, y las noches en los restaurantes de Plaka, al pie de la acrópolis, donde infaliblemente íbamos a cenar. Y juntos recorrimos museos, iglesias ortodoxas, templos, y la islita de Hydra. Cuando regresó a Londres, le dije a Patricia: «La pareja perfecta existe. Aurora y Julio han sabido realizar ese milagro: un matrimonio feliz». Pocos días después recibí carta de Julio anunciándome su separación. Creo que nunca me he sentido tan despistado.

12. La próxima vez que lo volví a ver, en Londres, con su nueva pareja, era otra persona. Se había dejado crecer el cabello y tenía unas barbas rojizas e imponentes, de profeta bíblico. Me hizo llevarlo a comprar revistas eróticas y hablaba de marihuana, de mujeres, de revolución, como antes de jazz y de fantasmas. Había siempre en él esa simpatía cálida, esa falta total de la pretensión y de las poses que casi inevitablemente aquejan a los escritores de éxito a partir de los cincuenta años, e incluso cabría decir que se había vuelto más fresco y juvenil, pero costaba trabajo relacionarlo con el de antes. Todas las veces que lo vi después -en Barcelona, en Cuba, en Londres o en París, en congresos o mesas redondas, en reuniones sociales o conspiratorias- me quedé cada vez más perplejo que la vez anterior: ¿era él? ¿Era Julio Cortázar? Desde luego que lo era, pero como el gusanito que se volvió mariposa o el fakir del cuento que luego de soñar con maharajás, abrió los ojos y estaba sentado en un trono, rodeado de cortesanos que le rendían pleitesía.

13. Este otro Julio Cortázar, me parece, fue menos personal y creador como escritor que el primigenio. Pero tengo la sospecha de que, compensatoriamente, tuvo una vida más intensa y, acaso, más feliz que aquella de antes, en la que, como dijo, la existencia se resumía para él en un libro. Por lo menos, todas las veces que lo vi me pareció joven, exaltado, dispuesto. Pero, eso, no hay manera de saberlo, desde luego.

14. Si alguien lo sabe, debe ser Aurora, por supuesto. Yo no cometo la impertinencia de preguntárselo. Ni siquiera hablamos mucho de Julio, en estos días calientes de Deyá, aunque él está siempre allí, detrás de todas las conversaciones, llevando el contrapunto con la destreza de entonces. La casita, medio escondida entre los olivos, los cipreses, las buganvilias, los limoneros y las hortensias, tiene 
el orden y la limpieza mental de Aurora, naturalmente, y es un inmenso placer sentir, en la pequeña terraza junto a la quebrada, la decadencia del día, la brisa del anochecer, y ver aparecer el cuerno de la luna en lo alto del cerro. De rato en rato, oigo desafinar una trompeta. No hay nadie por los alrededores. El sonido sale, pues, de ese cartel del fondo de la sala, donde un chiquillo larguirucho y lampiño, con rel pelo cortado a lo alemán y una camiseta de mangas cortas el Julio Cortázar que yo conocí- juega a su juego favorito.

Copyright M. Vargas Llosa y El País 